\title{
Diagnosis of Hepatoid Carcinoma of Extrahepatic Origins: Cell Markers and Pathologic Standards
}

\author{
Belinda Sun ${ }^{1}$, Richa Jain ${ }^{1}$, John Cunningham ${ }^{2}$ and Achyut Bhattacharyya*1 \\ ${ }^{1}$ Department of Pathology, Arizona \\ ${ }^{2}$ Department of Medicine, Arizona
}

*Corresponding author: Achyut Bhattacharyya, Department of Pathology, Arizona

\section{ARTICLE INFO}

Received: 慧 February 04, 2019

Published: 豐 February 26, 2019

Citation: Sun B, Jain R, Cunningham J, Bhattacharyya A. Diagnosis of Hepatoid Carcinoma of Extrahepatic Origins: Cell Markers and Pathologic Standards. Biomed J Sci \& Tech Res 15(2)-2019. BJSTR. MS.ID.002666.

Keywords: Hepatoid Adenocarcinoma, Alpha Fetal Protein, HepPar-1, Glypican-3

Abbreviations: Hepatoid adenocarcinoma (HAC); alpha fetal protein (AFP); bile salt export pump (BSEP) and multidrug-resistance protein 3 (MDR3); Endoscopic Retrograde Cholangiopancreatography (ERCP)
ABSTRACT

Background: Hepatoid adenocarcinoma (HAC) is a rare carcinoma showing hepatocellular differentiation but arising from extrahepatic organs. We herein have reported four HAC cases and reviewed literature to summarize the pathologic standards and biomarkers for diagnosis of HACs.

Objectives and Methods: Cases diagnosed as HAC at the University of Arizona Medical Center Tucson were retrospectively reviewed. Relevant literature in the PubMed database prior to October, 2018 were reviewed and summarized.

Results and conclusion: About $72 \%$ of reported HACs were originated from stomach, $9 \%$ from ovary, $7 \%$ from lung, $6 \%$ from pancreas, $2 \%$ from gallbladder or urinary bladder and rare cases from uterus, esophagus, jejunum, colon, rectum, or extrahepatic bile duct. Diagnosis of HAC can be challenging especially at the metastatic stage of disease with multiple organs' involvement. Hepatocellular markers identify hepatocellular differentiation with variable sensitivity for the diagnosis of HACs from different origins. AFP expression was found in more than $90 \%$ of gastric, ovarian and urinary gallbladder HACs but only in $57 \%$ of pancreatic HACs. HepPar-1 was positive in $100 \%$ of pancreatic, gallbladder and urinary gallbladder HACs but only in 31\% of gastric HACs. Glypican-3 is positive in almost all HACs tested except one gastric HAC. Differentiating HAC versus hepatocellular carcinoma is challenging due to the striking similarity in morphology and immunoprofile. Some tumor markers may help to make differentiation: serum tumor marker CA125 was elevated in $75 \%$ of ovarian HACs, and serum CEA was increased in 63\% of gastric HACs; CK19 and CK7 were often strongly positive in HACs but rarely positive in hepatocellular carcinomas. Some newly identified markers such as bile salt export pump (BSEP) and multidrug-resistance protein 3 (MDR3) have been reported in distinguishing HAC from hepatocellular carcinoma but need to be further validated.

\section{Introduction}

Hepatoid adenocarcinoma (HAC) or hepatoid carcinoma is a rare (adeno)carcinoma with hepatocellular differentiation but arises from extrahepatic tissues. HAC was initially reported as an alpha fetal protein (AFP) producing tumor of gastric origin in 1970 [1]. Later, Ishikura et al. [2] proposed the term "hepatoid carcinoma" for AFP-producing ovarine adenocarcinoma in 1987. Up to date, there have been approximately 408 HAC cases from different origins reported in the English literature. Most of HACs have arisen in stomach, much less in ovary, lung, pancreas, gallbladder, and rare in uterus, esophagus, jejunum, colon, rectum, or extrahepatic bile duct. The diagnostic standards in defining "hepatoid" has been variable in practice. Some HACs have been diagnosed based on elevated serum AFP as a defining feature of hepatocellular differentiation, some based on morphological features of hepatocytes, and some required immunohistochemical expression of hepatocellular markers including AFP, HepPar1, glypican-3, arginase, albumin or Sall-4 $[3,4]$. The diagnosis of HAC can be challenging, especially in differentiating extrahepatic HAC with liver metastasis versus 
hepatocellular carcinoma with extrahepatic metastasis. We herein have reported four challenging HAC cases encountered in our institute and reviewed HACs reported in English literature to summarize the characteristic features and useful markers up to date for the pathologic diagnosis of HACs.

\section{Materials and Methods}

This study was approved by Internal Review Board of University of Arizona for human research and conducted following the guidelines for human research. The HAC cases were collected in our pathology department in 2003 and from year 2012 to 2016. The patients' clinical history and pathologic slides were collected and reviewed. The PubMed database prior to October 2018 were searched to identify relevant medical literature by using keywords "hepatoid carcinoma", "alpha fetoprotein-producing tumor" "fetal type gastrointestinal adenocarcinoma" and "yolk sac-like tumor". A manual search of all relevant articles were conducted. The studies with full text available were reviewed.

\section{Case Reports}

\section{Case One}

A 49 years old male presented with obstructive jaundice and increased alkaline phosphatase. Endoscopic Retrograde Cholangiopancreatography (ERCP) show an obstructive mass in the extrahepatic duct (Figure $1 \mathrm{~A}$ ). A biopsy was performed (Figure 1B) during ERCP. No liver lesion was identified. The biopsy showed neoplastic polygonal cells with enlarged, centrally located round nuclei, prominent nucleoli, and abundant eosinophilic cytoplasm (Figure 1C). Macrovesicular fatty changes and intracellular Mallory like bodies (Figure 1D) are present, mimicking hepatocytes. Immunostain for polyclonal CEA showed canalicular pattern of positive staining (Figure 1E). The tumor cells are strongly positive for CK10/11 (Figure 1F) but negative for CK7 and KA4 (CK14, CK15, CK16 and CK19). A diagnosis of hepatoid carcinoma of extrahepatic bile duct was made.

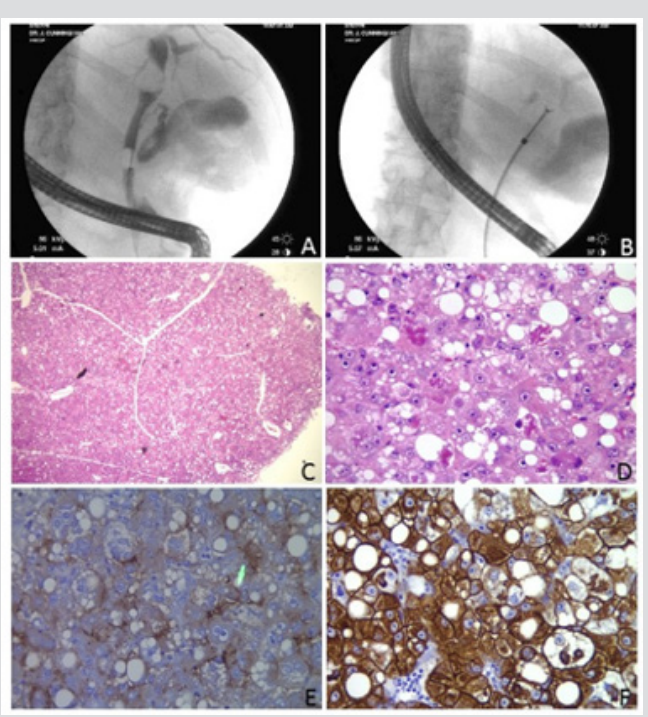

Figure 1.

\section{Case Two}

A 53 years old male with a medical history of coronary artery disease, hypothyroidism and pemphigus vulgaris, presented with orthopnea and generalized weakness and stridor two weeks later. He was diagnosed with neuromuscular disorder with high suspicion for myasthenia gravis or paraneoplastic syndrome. The patient continued to have respiratory failure on ventilator and passed away in one week. An autopsy was performed. A 17x14x10 cm large multi-nodular cystic mass was found at the head of the pancreas. The tumor was infiltrative and invading peri-pancreatic soft tissue. Microscopic examination showed polygonal neoplastic cells with abundant granular eosinophilic cytoplasm, centrally located nuclei, open chromatin and prominent nucleoli. The tumor cells formed nest, trabecular or peudoglandular architecture. Intracellular fat macrovesicles and eosinophilic globules were present, mimicking hepatocellular carcinoma (Figure 2A). Immunohistochemical stains showed that the tumor cells were positive for HepPar-1(Figure 2B), CK19 (Figure 2C) and pancytokeratin, and negative for vimentin, CD56, synaptophysin and chromogranin. A diagnosis of hepatoid adenocarcinoma of pancreas was made. In addition, a $2.2 \mathrm{~cm}$ hemorrhagic lesion in right kidney showed classic morphologic features of clear cell renal cell carcinoma. No lesion was identified in liver or other organs.

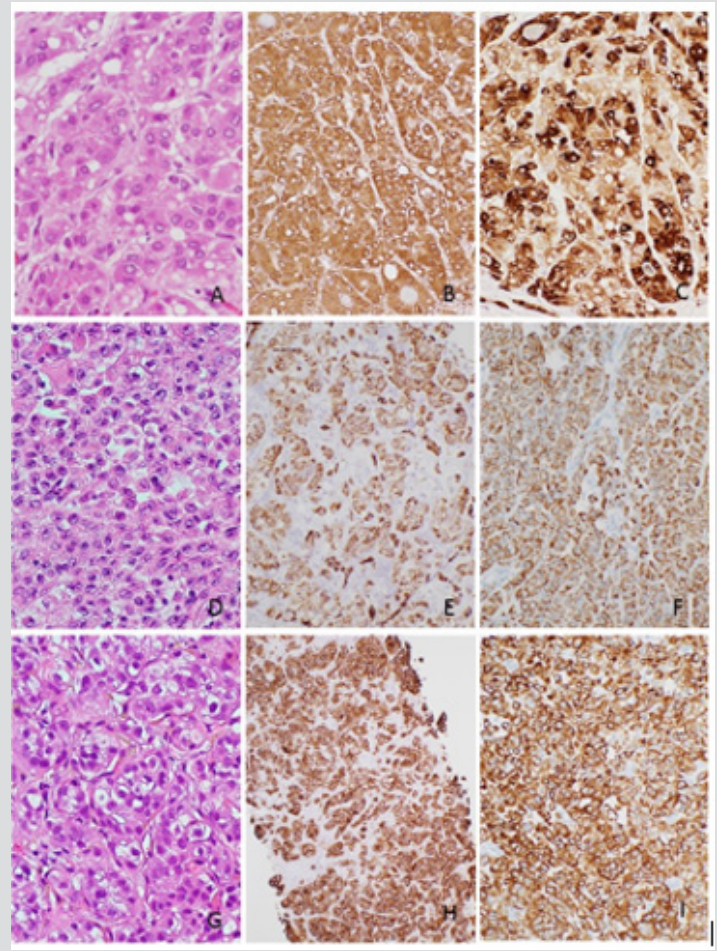

Figure 2.

\section{Case Three}

A 58 years old female with a medical history of thyroid carcinoma post thyroidectomy, presented with persistent right hip pain. Abdominal MRI showed multiple metastasis throughout liver with the largest lesion measuring $2.7 \mathrm{~cm}$. Osseous metastasis involved 
lower thoracic vertebra and right iliac bone. A $4.7 \mathrm{~cm}$ enhancing tumor in the left lung base, was most suggestive of a primary lung carcinoma. In addition, there were a $5.8 \mathrm{~cm}$ cystic renal cell carcinoma and a $4.2 \mathrm{~cm}$ degenerative right adrenal adenoma. A biopsy on the bone lesion at an outside hospital reported "suggestive of adenocarcinoma, unknown primary". The liver biopsy in our institution showed poorly differentiated carcinoma with nested, pleomorphic polygonal cells with eosoinophilic cytoplasma and hyperchromatic nuclei (Figure 2D). Immunohistochemical stains showed that the tumor cells were strongly positive for HepPar-1 (Figure 2E), CK19 (Figure 2F), CK7, weakly nuclear positive for CDX2 and Pax 8, and negative for TTF1, CK20, CD10, RCC, estrogen receptor, progesterone receptor and vimentin. A diagnosis of hepatoid carcinoma was made but the tumor origin remained uncertain. The patient was treated with chemotherapy but passed away three months later.

\section{Case Four}

A 61 years old male former smoker with a medical history of spontaneous pneumothorax presented with severe abdominal pain. CT imaging studies showed small bowel obstruction and intussusception with perforation, multiple enhancing, necrotic masses scattered throughout the abdomen and pelvis. Bilateral lung nodules and a $5.6 \mathrm{~cm}$ mediastinal left upper lobe lung mass were present and considered as a bronchogenic carcinoma. A $2 \mathrm{~cm}$ exophytic lesion at the left renal lower pole was also present. No lesion was identified in liver. The patient had small bowel resection which showed multiple poorly differentiated carcinoma infiltrating from serosal aspect through the full thickness of the bowel wall with area of tumor perforation. The tumor cells arranged in trabeculae structures with focally pseudo-glandular formation. The tumor cells possessed abundant eosinophilic, granular cytoplasm and vesicular nuclei with prominent nucleoli (Figure 2G). Immunohistochemical stains showed that the tumor cells were positive for HepPar-1 (Figure 2H), CK7 (Figure 2I) and CK10/11, and negative for CK20, TTF1, Napsin-A, RCC, PAX-8, PSA, PSAP, S100, HMB45, and Melan A. The morphology and immunohistochemical stains support a diagnosis of hepatoid adenocarcinoma with uncertain primary, likely lung origin based on clinical correlation. The patient was transferred to hospice care.

\section{Results and Discussion}

These four HAC cases emphasize the challenge in diagnosing HAC based on morphology and immunoprofile of the tumor. We have reviewed the reported HACs in the English literature to summarize the diagnostic standards of HACs and the markers which may help to define the primary origin. Table 1 lists the summary of 408 HACs from variable organs reported in the English literature. $72 \%$ of reported HACs were originated from stomachs, about $9 \%$ from ovaries, $7 \%$ from lung, $6 \%$ from pancreas, $2 \%$ from gallbladder or urinary bladder and rare case from uterus, esophagus, jejunum, colon, rectum, and extrahepatic bile duct. Up to date, our case \#1 is the third case of HAC arising from extrahepatic bile duct $[12,13]$. Hepatoid adenocarcinoma was initially proposed by Ishikura et al. [2] to describe seven excessive AFP producing adenocarcinoma. Later in 1993, Motoyama et al. [5] subdivided gastric adenocarcinoma with high AFP-production into three subtypes: hepatoid type, fetal gastrointerstinal type and yolk sac tumor-like. The hepatoid type represents the best recognizable morphologic features of hepatocellular differentiation.

Table 1.

\begin{tabular}{|c|c|c|c|c|c|c|c|c|c|c|c|c|}
\hline $\begin{array}{c}\text { Primary } \\
\text { organ }\end{array}$ & $N$ & $\begin{array}{r}\text { Male/ } \\
\text { Female }\end{array}$ & $\begin{array}{l}\text { Av- } \\
\text { er- } \\
\text { age } \\
\text { Age }\end{array}$ & AFP* & $\begin{array}{l}\text { HepPar } \\
-1^{*}\end{array}$ & Glyp -3* & pCEA* & Arg -1* & $\begin{array}{c}\text { Albu- } \\
\text { min } \\
*\end{array}$ & $\begin{array}{l}\text { PIVKA } \\
\text { - II* }\end{array}$ & $\begin{array}{l}\text { alpha1anti- } \\
\text { trypsin* }\end{array}$ & $\begin{array}{l}\text { alpha1- } \\
\text { chymotryp- } \\
\quad \sin ^{*}\end{array}$ \\
\hline $\begin{array}{c}\text { Stomach } \\
\text { [1,3, } \\
6,14,15]\end{array}$ & $\begin{array}{c}295 \\
(72 \%)\end{array}$ & $\begin{array}{l}198 / 67 \\
(2.9: 1)\end{array}$ & 63 & $\begin{array}{c}209 / 230 \\
(91 \%)\end{array}$ & $\begin{array}{l}15 / 47 \\
(32 \%)\end{array}$ & $\begin{array}{c}27 / 28 \\
(96.4 \%)\end{array}$ & & $\begin{array}{l}6 / 17 \\
(35 \%)\end{array}$ & $\begin{array}{l}16 / 18 \\
(89 \%)\end{array}$ & $?$ & $7 / 8$ (88\%) & \\
\hline $\begin{array}{c}\text { Ovary } \\
{[2,16,17]}\end{array}$ & $\begin{array}{c}38 \\
(9 \%)\end{array}$ & NA & 53 & $\begin{array}{l}28 / 29 \\
(97 \%)\end{array}$ & $\begin{array}{c}6 / 7 \\
(86 \%)\end{array}$ & $?$ & $\begin{array}{c}5 / 6 \\
(83 \%)\end{array}$ & $?$ & $\begin{array}{l}10 / 10 \\
(100 \%)\end{array}$ & $?$ & $\begin{array}{l}10 / 12 \\
(83 \%)\end{array}$ & $\begin{array}{c}7 / 7 \\
(100 \%)\end{array}$ \\
\hline $\begin{array}{l}\text { Lung } \\
\text { [18] }\end{array}$ & $\begin{array}{c}30 \\
(7 \%)\end{array}$ & $\begin{array}{l}29 / 1 \\
(29: 1)\end{array}$ & 64 & $\begin{array}{l}19 / 22 \\
(86 \%)\end{array}$ & $\begin{array}{c}2 / 4 \\
(50 \%)\end{array}$ & $\begin{array}{c}2 / 2 \\
(100 \%)\end{array}$ & $\begin{array}{c}6 / 6^{* *} \\
(100 \%)\end{array}$ & $?$ & $\begin{array}{c}1 / 1 \\
(100 \%)\end{array}$ & $?$ & $?$ & $?$ \\
\hline $\begin{array}{l}\text { Pancreas } \\
{[19,20]}\end{array}$ & $\begin{array}{c}27 \\
(6.6 \%)\end{array}$ & $\begin{array}{l}17 / 10 \\
(1.7: 1)\end{array}$ & 65 & $\begin{array}{l}12 / 22 \\
(54 \%)\end{array}$ & $\begin{array}{c}5 / 5 \\
(100 \%)\end{array}$ & $2 / 2(100 \%)$ & $\begin{array}{l}2 / 2 * * * \\
(100 \%)\end{array}$ & $?$ & $\begin{array}{c}1 / 1 \\
(100 \%)\end{array}$ & $\begin{array}{c}2 / 2 \\
(100 \%)\end{array}$ & $?$ & $?$ \\
\hline $\begin{array}{c}\text { Gallbladder } \\
\text { [21] }\end{array}$ & $\begin{array}{c}9 \\
(2 \%)\end{array}$ & $\begin{array}{c}3 / 6 \\
(0.5: 1)\end{array}$ & 67 & $\begin{array}{c}6 / 9 \\
(67 \%)\end{array}$ & $\begin{array}{c}6 / 6 \\
(100 \%)\end{array}$ & $?$ & $\begin{array}{c}3 / 5 \\
(60 \%)\end{array}$ & $?$ & $?$ & $?$ & $?$ & $?$ \\
\hline $\begin{array}{c}\text { Urinary } \\
\text { bladder } \\
{[10]}\end{array}$ & $\begin{array}{c}9 \\
(2 \%)\end{array}$ & $\begin{array}{c}7 / 3 \\
(2.3: 1)\end{array}$ & 64 & $\begin{array}{c}9 / 9 \\
(100 \%)\end{array}$ & $\begin{array}{c}4 / 4 \\
(100 \%)\end{array}$ & & $\begin{array}{l}6 / 6^{* * * *} \\
(100 \%)\end{array}$ & & $\begin{array}{c}6 / 6 \\
(100 \%)\end{array}$ & & $6 / 6(100 \%)$ & \\
\hline Summary & 408 & $2.9: 1$ & 63 & $82 \%$ & $78 \%$ & $98 \%$ & & $35 \%$ & $97 \%$ & $100 \%$ & $90 \%$ & $100 \%$ \\
\hline
\end{tabular}


The fetal gastrointestinal type morphologically appears as tubular adenocarcinomas, producing high level of AFP and possibly derived from fetal gastrointestinal epithelium. The yolk sac tumor-like type morphologically represents yolk sac tumor with production of AFP and possibly derived from yolk sac metaplasia. Recently, Arora et al [6] applied three categories to tumors with hepatocellular differentiation as type I (hepatoid), type II (fetal type gastrointestinal adenocarcinoma), and type III (positive for at lest two hepatocyte specific markers but lacking morphological evidence of hepatocellular differentiation). The WHO classification of tumors in digestive system defines gastric HAC as an adenocarcinoma composed of large polygonal eosinophilic hepatocyte-like neoplastic cells expressing AFP detected in situ or in serum [7]. Although HAC is defined mostly based on elevated serum AFP as a feature of hepatocellular differentiation, AFP production is not necessary in the diagnosis of many reported HACs. As shown in (Table 1), AFP has been tested in about $78 \%$ of reported HACs. Moreover, not all HACs express AFP: AFP elevation or expression has been found in $91 \%$ of gastric HACs, $97 \%$ of ovary HACs, $100 \%$ of urinary gallbladder HACs, but only $57 \%$ of pancreatic HACs. In those HACs not tested for AFP, some have been diagnosed based on morphologic features of hepatocellular differentiation only, and some diagnosed based on expressing at least one of the other hepatocellular markers including HepPar1, glypican-3, arginase, albumin or Sall-4.

A variety of markers with variable specificity to hepatocellular differentiation have been utilized for the diagnosis of HACs. As shown in Table 1, HepPar 1 has been considered a specific marker for hepatocytes but only positive in 31\% of gastric HACs tested. However, HepPar 1 has been positive in 100\% of pancreatic, gallbladder and urinary gallbladder HACs tested. Our three HAC cases, one pancreatic HAC and two likely lung HACs are all positive for HepPar-1. Glypican-3 has not been often used for diagnosis of HACs but positive in almost all HACs tested except one gastric HAC. Albumin has been tested in about 36 cases and found positive in all ovarian, urinary bladder HACs and $86 \%$ of gastric HACs tested. Alpha-1 antitrypsin and alpha-1 chemotrypsin have also been used and showed 83-100\% positivity. Arginase-1 has been tested in a small number of pancreatic HACs but only showed positive in 35\%. PIVKA-II has been tested in two pancreatic HAC cases and showed positive. In a summary, it appears that HACs from different organs may show different expression patterns of hepatocellular markers. Gastric HACs express AFP, glypican-3, but less likely express HepPar-1. On the other hand, all pancreatic HACs express HepPar-1, glypican-3 but only 53\% express AFP. Urinary bladder HACs are positive for both AFP and HepPar-1. Glypican-3 is a sensitive marker in all tested HACs. Knowing these expression patterns may help us to choose proper markers for diagnosis of hepatocellular differentiation in HACs of different primary organs.

The major differential diagnosis of a tumor with hepatocellular differentiation includes HAC, hepatocellular carcinoma and hepatoid yolk sac tumor. To differentiate hepatoid yolk sac tumor, the patient's young age, tumor location of ovary or testes, and PLAP or CD117 expression help to make the diagnosis. However for hepatocellular carcinoma, due to similar clinical and pathological features, HAC may closely resemble and even be indistinguishable from hepatocellular carcinoma. Clinical correlation, laboratory tests and imaging studies are always critical as well as the pathologic examination. Clinically, a typical dynamic imaging showing intense arterial uptake followed by "washout" of contrast in the venous and a medical history of cirrhosis, hepatitis C or B would suggest a diagnosis of hepatocellular carcinoma. Table 1 lists some clinical characters of HACs. HACs are mostly in old age patients (average 63 years old), male predominant except in gallbladder HACs, clinically aggressive and frequently metastasize to lymph nodes. However, when the clinical presentations are atypical, pathologic diagnosis becomes necessary for the differential diagnosis. Morphologically differentiating HAC versus HCC is challenging because of the striking morphologic similarity between these two tumors. Some authors suggested that polygonal tumor cells proliferating in both trabecular and intestinal-like structures are more indicative of HAC [8].

The hepatocellular markers are less useful in distinguishing HAC versus hepatocellular carcinoma; instead, while serum AFP has long been used for screening and diagnosis of hepatocellular carcinoma, HACs with high AFP may be incorrectly diagnosed as hepatocellular carcinoma. Some specific serum tumor markers such as CA125, CEA and CA19-9 may help to differentiate AFP producing HAC from hepatocellular carcinoma. As shown in Table 2 , serum CA125 is elevated in $75 \%$ of ovarian HACs, serum CEA is increased in $63 \%$ of gastric HACs and serum CA19-9 is increased in a urinary bladder HAC and $14 \%$ pancreatic HACs. Some cell markers including CK19, CK7, CK20, CK8/18, CK10/11, polyclonal CEA, and EMA have been utilized in the diagnosis of HACs. CK19 appears to be frequently positive in HACs. As shown in Table 2, CK19 is positive in $100 \%$ of gastric and gallbladder HACs tested but is reported positive in only $15 \%$ of hepatocellular carcinoma. Three of our 4 HACs were tested for CK19 and two were positive. Thus, if a morphologically hepatoid tumor is positive for CK19, HAC is strongly suggested. 
Table 2.

\begin{tabular}{|c|c|c|c|c|c|c|c|c|c|c|c|c|c|c|c|c|}
\hline $\begin{array}{c}\text { Primary } \\
\text { organs }\end{array}$ & CK19 & CK7 & $\begin{array}{l}\text { Serum } \\
\text { CA125 }\end{array}$ & $\begin{array}{l}\text { Serum } \\
\text { CA19- } \\
9\end{array}$ & CK20 & CK8/18 & $\begin{array}{c}\text { TTF } \\
1\end{array}$ & P63 & $\begin{array}{l}\text { CDX } \\
2\end{array}$ & $\begin{array}{c}\text { Serum } \\
\text { CEA }\end{array}$ & CEA & EMA & CD10 & CD56 & $\begin{array}{l}\text { Chro- } \\
\text { mo } \\
\text { granin }\end{array}$ & $\begin{array}{c}\text { Inhib- } \\
\text { in }\end{array}$ \\
\hline $\begin{array}{c}\text { Stomach } \\
\text { [1, 3, } \\
6,14,15]\end{array}$ & $\begin{array}{l}16 / 16 \\
(100 \%)\end{array}$ & $?$ & & & $\begin{array}{l}5 / 13 \\
(39 \%)\end{array}$ & $\begin{array}{l}17 / 17 \\
(100 \%)\end{array}$ & $?$ & $?$ & & $\begin{array}{r}15 / 24 \\
(63 \%)\end{array}$ & $\begin{array}{l}27 / 36 \\
(75 \%)\end{array}$ & & & & & \\
\hline $\begin{array}{c}\text { Ovary } \\
{[2,16,} \\
17]\end{array}$ & $\begin{array}{c}2 / 8 \\
(25 \%)\end{array}$ & $\begin{array}{c}6 / 9 \\
(67 \%)\end{array}$ & $\begin{array}{l}15 / 20 \\
(75 \%)\end{array}$ & & $\begin{array}{c}2 / 9 \\
(22 \%)\end{array}$ & $\begin{array}{c}2 / 2 \\
(100 \%)\end{array}$ & & & & & $\begin{array}{l}12 / 17 \\
(71 \%)\end{array}$ & $\begin{array}{c}4 / 6 \\
(67 \%)\end{array}$ & $\begin{array}{c}1 / 4 \\
(25 \%)\end{array}$ & & & $\begin{array}{c}2 / 7 \\
(29 \%)\end{array}$ \\
\hline $\begin{array}{c}\text { Lung } \\
{[18]}\end{array}$ & $?$ & $\begin{array}{c}2 / 4 \\
(50 \%)\end{array}$ & $?$ & & $0 / 3$ & $\begin{array}{c}2 / 2 \\
(100 \%)\end{array}$ & $0 / 3$ & $0 / 2$ & $0 / 1$ & & & & & & & \\
\hline $\begin{array}{c}\text { Pancreas } \\
{[19,20]}\end{array}$ & & $0 / 1$ & & $\begin{array}{l}2 / 14 \\
(14 \%)\end{array}$ & & $\begin{array}{c}1 / 1 \\
(100 \%)\end{array}$ & & & & $\begin{array}{l}2 / 11 \\
(18 \%)\end{array}$ & & & & & & \\
\hline $\begin{array}{l}\text { Gallblad- } \\
\text { der [21] }\end{array}$ & $\begin{array}{c}4 / 4 \\
(100 \%)\end{array}$ & $\begin{array}{c}2 / 7 \\
(29 \%)\end{array}$ & $?$ & $?$ & $0 / 2$ & $\begin{array}{c}4 / 4 \\
(100 \%)\end{array}$ & $?$ & $?$ & $?$ & $?$ & & & & $\begin{array}{c}1 / 1 \\
(100 \%)\end{array}$ & & \\
\hline 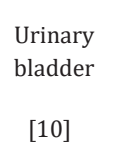 & $?$ & $?$ & & $\begin{array}{c}1 / 1 \\
(100 \%)\end{array}$ & $?$ & $\begin{array}{c}1 / 1 \\
(100 \%)\end{array}$ & & & & $\begin{array}{c}1 / 1 \\
(100 \%)\end{array}$ & $\begin{array}{c}1 / 1 \\
(100 \%)\end{array}$ & $\begin{array}{l}1 / 1 \\
(100 \\
\%)\end{array}$ & & & $\begin{array}{c}1 / 5 \\
(20 \%)\end{array}$ & \\
\hline
\end{tabular}

Another significant marker is CK7 which is positive in $67 \%$ of ovarian HACs and $50 \%$ of lung HACs tested, but CK7 is positive in only about $5 \%$ of hepatocellular carcinoma. Polyclonal CEA may be useful in diagnosis of lung HAC as showing diffuse staining pattern in 5 of 6 lung HAC tested, but less useful in urinary bladder and pancreatic HAC as most showing canalicular pattern similar to hepatocytes. Our case \# 1 , the extrahepatic bile duct HAC, also shows canalicular pattern of polyclonal CEA staining. The organ-specific markers have not been shown useful in identifying the primary origin of HAC; such as TTF1, a marker for lung, has been found negative in all three lung HACs tested in literature and negative in our two likely lung HAC cases. There is no identified marker which can be used for pancreatic or gallbladder HACs. Other markers, such as PLUNG [9] MUC1, CD10, A1-antitrypsin, alpha-1-chymotrypsin, SALL4 [4], bile salt export pump (BSEP) and multidrug-F.

\section{References}

1. Bourreille J, Metayer P, Sauger F, Matray F, Fondimare A (1970) [Existence of alpha feto protein during gastric-origin secondary cancer of the liver]. Presse Med 78(28): 1277-1278.

2. Ishikura H, Scully RE (1987) Hepatoid carcinoma of the ovary. A newly described tumor. Cancer 60(11): 2775-2784.

3. Osada M, Aishima S, Hirahashi M, Takizawa N, Takahashi S, et al. (2014) Combination of hepatocellular markers is useful for prognostication in gastric hepatoid adenocarcinoma. Hum Pathol 45(6): 1243-1250.

4. Ushiku T, Shinozaki A, Shibahara J, Iwasaki Y, Tateishi Y, et al. (2010) SALL4 represents fetal gut differentiation of gastric Cancer, and is diagnostically useful in distinguishing hepatoid gastric carcinoma from hepatocellular carcinoma. Am J Surg Pathol 34(4): 533-540.
5. Motoyama T, Aizawa K, Watanabe H, Fukase M, Saito K, et al. (1993) alpha-Fetoprotein producing gastric carcinomas: a comparative study of three different subtypes. Acta Pathol 43(11): 654-661.

6. Arora K, Bal M, Shih A, Moy A, Zukerberg L, et al. (2017) Fetal-type gastrointestinal adenocarcinoma: a morphologically distinct entity with unfavourable prognosis. J Clin Pathol 71(3): 221-227.

7. (2010) WHO classification of Tumours of the Digestive System. The International Agency for Research on Cancer: Lyon.

8. Su JS, Chen YT, Wang RC, Wu CY, Lee SW, et al. (2013) Clinicopathological characteristics in the differential diagnosis of hepatoid adenocarcinoma: a literature review. World J Gastroenterol 19(3): 321-327.

9. Sentani K, Oue N, Sakamoto N, Arihiro K, Aoyagi K, et al. (2008) Gene expression profiling with microarray and SAGE identifies PLUNC as a marker for hepatoid adenocarcinoma of the stomach. Mod Pathol 21(4): 464-475.

10. Sekino Y, Mochizuki H, Kuniyasu H (2013) A 49-year-old woman presenting with hepatoid adenocarcinoma of the urinary bladder: a case report. J Med Case Rep 7: 12.

11. Fujikura K, Yamasaki T, Otani K, Kanzawa M, Fukumoto T, et al. (2016) BSEP and MDR3: Useful Immunohistochemical Markers to Discriminate Hepatocellular Carcinomas From Intrahepatic Cholangiocarcinomas and Hepatoid Carcinomas. Am J Surg Pathol 40(5): 689-696.

12. Yorita K, Sasaki S, Kawada A, Okazaki M, Yamai H, et al. (2017) Hepatoid Adenocarcinoma of the Extrahepatic Bile Duct in a Patient with Polysplenia Syndrome. Intern Med 56(4): 401-407.

13. Wang Y, Liu YY, Han GP (2013) Hepatoid adenocarcinoma of the extrahepatic duct. World J Gastroenterol 19(22): 3524-3527.

14. Yoshizawa J, Ishizone S, Ikeyama M, Nakayama J (2017) Gastric hepatoid adenocarcinoma resulting in a spontaneous gastric perforation: a case report and review of the literature. BMC Cancer 17(1): 368.

15. Inagawa S, Shimazaki J, Hori M, Yoshimi F, Adachi S, et al. (2001) Hepatoid adenocarcinoma of the stomach. Gastric Cancer 4: 43-52. 
16. Mahmood H, Fatima H, Faheem M (2017) Metastatic hepatoid carcinoma of ovarian origin- a case report from northern Pakistan. Gynecol Oncol Rep 21: 24-27.

17. Lakhotia M, Pahadiya HR, Choudhary A, Gandhi R, Purohit RC (2016) A rare case of hepatoid carcinoma of the ovary with pancytopenia and hypocellular marrow. Indian J Med Paediatr Oncol 37(4): 307-309.

18. Grossman K, Beasley MB, Braman SS (2016) Hepatoid adenocarcinoma of the lung: Review of a rare form of lung cancer. Respir Med 119: 175179.

\section{ISSN: 2574-1241}

DOI: 10.26717/BJSTR.2019.15.002666

Achyut Bhattacharyya. Biomed J Sci \& Tech Res

(CC) This work is licensed under Creative

Submission Link: https://biomedres.us/submit-manuscript.php
19. Dogeas E, Peng L, Choti MA (2017) Hepatoid Adenocarcinoma of Unknown Primary Masquerading as a Pancreatic Tumor. J Gastrointest Surg 21(12): 2132-2134.

20. Chang JM, Katariya NN, Lam Himlin DM, Haakinson DJ, Ramanathan RK, et al. (2016) Hepatoid Carcinoma of the Pancreas: Case Report, Next-Generation Tumor Profiling, and Literature Review. Case Rep Gastroenterol 10(3): 605-612.

21. Koyama K, Maeda D, Tamura D, Narita C, Kudo Asabe Y, et al. (2017) Fetal Gut-Like Differentiation in Gallbladder Cancer. Hum Pathol 70: 27-34.

$\begin{array}{ll}\text { BIOMEDICAL } & \text { Assets of Publishing with us } \\ \text { RESEARCHES } & \text { - Global archiving of articles } \\ \text { ISSN: } 2574-1241 & \text { - Immediate, unrestricted online access } \\ \end{array}$

